\title{
Crop size as an index of chick provisioning in the Greater Flamingo Phoenicopterus roseus
}

\author{
MIGUEL A. RENDÓN, ${ }^{1 *}$ ARACELI GARRIDO, ${ }^{2}$ JOSÉ C. GUERRERO,${ }^{3}$ MANUEL RENDÓN-MARTOS ${ }^{4}$ \& \\ JUAN A. AMAT ${ }^{1}$ \\ ${ }^{1}$ Department of Wetland Ecology, Estación Biológica de Doñana (EBD-CSIC), Calle Américo Vespucio s/n, \\ 41092 Seville, Spain \\ ${ }^{2}$ Programa de Actuaciones de Conservación de Aves Acuáticas en Andalucía, Agencia de Medio Ambiente y Agua de \\ Andalucía, Consejería de Medio Ambiente, Junta de Andalucía, Parque Comercial Málaga Nostrum, Edif. Galia \\ Center, Calle Jaén 9-3a , 29004 Malaga, Spain \\ ${ }^{3}$ Laboratorio de Desarrollo Sustentable y Gestión Ambiental del Territorio (LDSGAT), Instituto de Ecología y Ciencias \\ Ambientales (IECA), Fac. Ciencias, Iguá 4225 Esq. Mataojo, 11400 Montevideo, Uruguay \\ ${ }^{4}$ Reserva Natural Laguna de Fuente de Piedra, Consejería de Medio Ambiente, Junta de Andalucía, Apartado 1, \\ 29520 Fuente de Piedra, Spain
}

\begin{abstract}
After being fed by their parents, Greater Flamingo chicks store food in their crops, which protrude outwards. We allocated the crop profiles of chicks to four categories to assess the relationship between body mass and crop profile variation, and so determine whether crop size can be used as an accurate index of the amount of food ingested, and to determine the timing and frequency of provisioning. We registered changes in body mass and crop fullness in eight chicks captured with turgid crops and kept in captivity until constant mass was achieved. The meal mass ingested by the chicks during each parental feeding was around $18 \%$ of net chick mass and varied greatly with crop profile. Mean transition times between the four crop profile categories ranged from 6 to $14 \mathrm{~h}$. Between 1998 and 2009, 34\% of chicks caught for ringing in a breeding colony had empty crops. From crop profiles recorded during the handling of chicks, it was estimated that approximately one-third of the chicks were fed in the evening and another third during the night. Our results have implications for the estimation of body condition indexes because body mass should be free of the influence of the mass of the food in the crop.
\end{abstract}

Keywords: body condition, digestion rate, feeding frequency, meal size, mixed models.

The study of chick provisioning strategies in birds is central to understanding the balance between the energy that adults allocate to self maintenance vs. that allocated to reproduction (Drent \& Daan 1980). Several methods have been proposed to evaluate chick provisioning patterns in colonial birds, e.g. counting of adults visiting the colony (Ojowski et al. 2001, Barlow \& Croxall 2002), estimation of the number of chicks that are fed and the quantity of food received by chicks during the rearing period (Ricklefs et al. 1985, Bolton 1995, Phillips \& Hamer 2000). These methodologies have been used in species in which the same

*Corresponding author.

Email: ma_rendon@ebd.csic.es individuals may be recaptured during the period of parental dependence and in which the manipulations have no negative impact on breeding success. However, the possibility of resampling the same individuals may be limited in many species because of the difficulty of recapturing individual chicks, the stress produced from handling chicks, or the disturbance that the captures may have on breeding success.

Thus, when there is no possibility of capturing chicks, the quantity of food received may be estimated by counting and identifying their food items (Dawson \& Bortolotti 2002). Often this is not feasible because the composition of the diet may not be differentiated in terms of discreet items (e.g. secretions or food partially digested by adults). 
In such instances, the usual approach has been to record the time that adults allocate to chick provisioning, either quantitatively (Cézilly et al. 1994) or semi-quantitatively (Lecomte et al. 2006). Yet, in some cases the particular behaviour of the species or difficulty in accessing breeding sites may limit the recording of the duration of feeding. It then becomes necessary to rely on indirect measures to estimate the quantity of food ingested by chicks. Crop size is one such indirect measure of the amount of food consumed by chicks (Collopy 1986, Westmoreland \& Best 1987, Blockstein 1989) and by adults (Houston \& Houston 1976, Comeau \& Keppie 1988, Smith 1990, 1991).

Obtaining information on chick provisioning patterns in the colonial Greater Flamingo Phoenicopterus roseus is not straightforward because of adult behaviour and the difficulty of recapturing individual chicks. Flamingos feed their chicks with a secretion that adults produce in glands located in the upper digestive tract (Lang 1963, Ziswiler \& Farner 1972). After being fed by their parents, Greater Flamingo chicks store this food in their crops, which protrude outwards (Ziswiler \& Farner 1972), after which the food is gradually digested (Johnson \& Cézilly 2007). Furthermore, the adults commute between feeding and breeding sites at night (Rendón-Martos et al. 2000, Amat et al. 2005), which may complicate the estimation of the number of adults that arrive at the breeding site to feed their chicks. Moreover, the crowding of chicks in crèches and their great mobility do not easily allow for the recapture of individual birds to determine whether they have been fed. Nevertheless, variation in the crop size of chicks is evident (Fig. 1) and may provide a means of quantitatively evaluating how recently a chick has been fed.

Chick provisioning patterns of Greater Flamingos under field conditions are little known. The food ingestion rate has been estimated in captivity as $300-500 \mathrm{~g} /$ day (Batty et al. 2006), representing about $20 \%$ of chick body mass. This extra mass may affect estimations of body condition (Amat et al. 2007), so reliable ways to estimate the quantity of food inside a crop are necessary (Comeau \& Keppie 1988). In addition, the digestion rate of food in the crop of Flamingo chicks is not known, nor are the factors that may affect it. In other species it has been shown that food assimilation rates are affected by a chick's age, its net body mass and the quantity of food ingested (e.g. Bolton 1995,
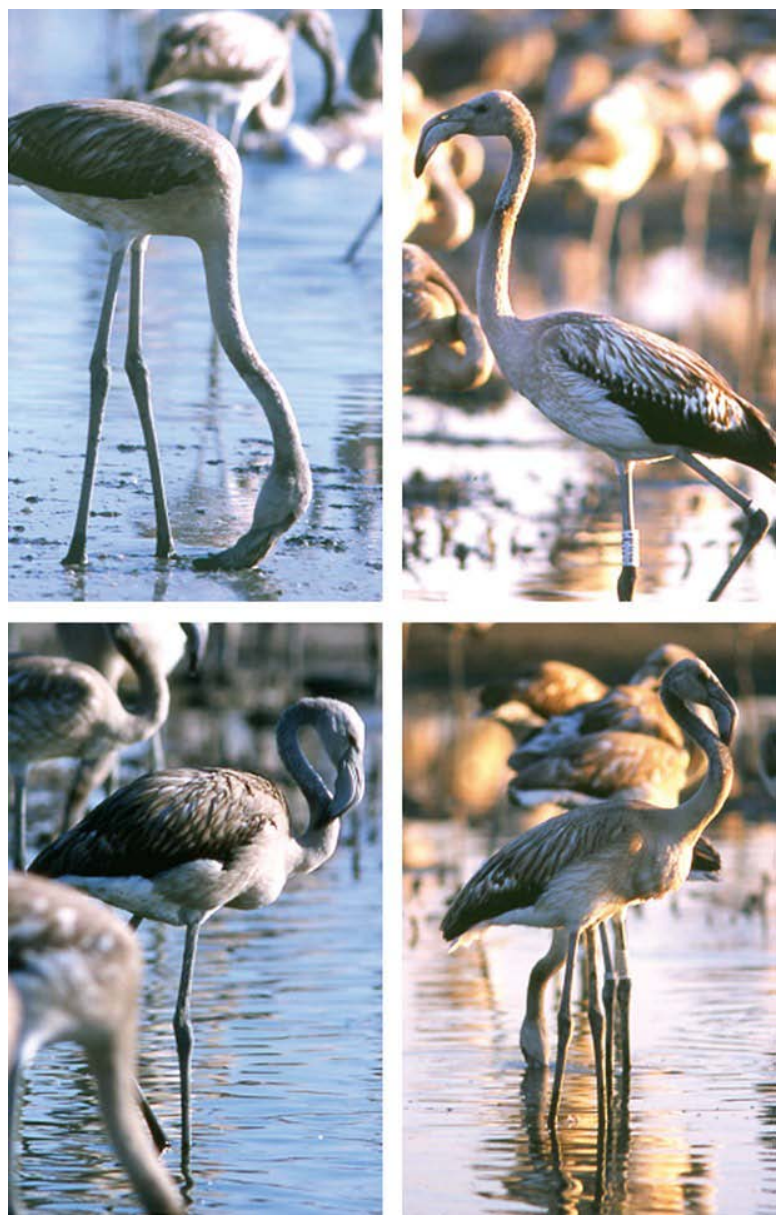

Figure 1. Pictures of Greater Flamingo chicks in which the differences in crop size between individuals are apparent.

Hamer et al. 1998, Granadeiro et al. 1999). Knowing the time required to assimilate the food stored in the crop may provide information on the time that a chick was last fed, which is necessary to estimate provisioning rates.

Here we seek to establish whether crop size may be used as an index of chick provisioning. We analysed variation in body mass of free-ranging Greater Flamingo chicks after being fed by their parents, as well as the relationship between the mass of food received by a chick and its crop size. In addition, we determined absorption rates of food in the crop in relation to food quantity and chick size. Finally, we assessed daily and annual variation in crop size frequencies to estimate both the effect of crop size on estimation of a chick's body condition and inter-annual variation in chick provisioning rates. 



\section{METHODS}

\section{Data recording}

Fieldwork was conducted at Fuente de Piedra Lake in southern Spain $\left(36^{\circ} 06 \mathrm{cN}, 4^{\circ} 45 \mathrm{cW}\right)$. Since 1986 , about $10 \%$ of the Greater Flamingo chicks in the crèche have been marked with rings bearing indi- vidual codes each time the Flamingos bred. Body measurements (lengths of tarsus, wing and bill and body mass) were also recorded from each ringed chick. From 1998 we also recorded the crop size of chicks, allocating it to four categories: (0) crop pro- file was slightly concave (i.e. empty), (1) crop pro- file slightly convex (trace), (2) crop profile convex (1/4-3/4 full) and (3) crop turgid (> 3/4 full) (Rendón et al. 2009). Crop size scores were rated annually by six observers, who differed between years.

To estimate the level of agreement in the alloca- tion of crop profile scores by different observers, we collected data from three colonies in southern Spain (Odiel Salt Pans, Marismas del Guadalquivir and Fuente de Piedra Lake). At each colony the crop size of 30 randomly selected chicks was scored independently by four observers. All observers usually carry out crop size assessments during chick ringing. Observers differed among colonies. The inter-observer agreement for crop profile scores was evaluated using the kappa coeffi- cient (Conger 1980). This statistic measures the agreement among multiple observers, taking into account the level of agreement that can occur by chance. We used both unweighted (Cohen's kappa, $\mathbf{j}$ ) and weighted (Light's kappa, $\mathbf{j w}$ ) agreement tests to evaluate nominal and ordinal agreement, respectively. Nominal rating treats any disagree- ment among crop size scores as a total disagree- ment, whereas ordinal rating takes into consideration the magnitude of disagreements of crop size differences depending on the ordinal value reported by each observer, and thus a weighted kappa statistic is computed. For ordinal rating, weights were squared differences between scores. Values of kappa between 0 and 0.20 indicate slight agreement, $0.21-0.40$ fair agreement,

0.41-0.60 moderate agreement, 0.61-0.80 sub- stantial agreement and 0.81-1.0 almost perfect agreement (Landis \& Koch 1977). Two-sided confi- dence intervals (95\%) of kappa coefficients were obtained by 1000 bootstrap pseudoreplications. Kappa statistics were carried out using the R pack- age psy (Falissard 2009). 
We selected eight chicks with turgid crops among those ringed in 1999. Immediately after ringing, these chicks were held in an enclosure located $250 \mathrm{~m}$ from the breeding site, and approxi- mately every $3 \mathrm{~h}$ (mean $=3.3 \mathrm{~h} \pm 0.3 \mathrm{sd}$, range $=$

2.7-3.9 h) we recorded their body mass with the same equipment used for the other ringed chicks (Pesola dynamometer to the nearest $50 \mathrm{~g}$ ). We started the recording of body mass between 05:30 and 06:30 h (GMT). Each time the chicks were weighed, their crop size was also recorded. The category of crop size assigned to each chick was the most frequent score allocated independently by three observers. Once there were no differences in both the body masses and crop size of chicks between two successive recordings, the chicks were released after supplying them with water and a vitamin supplement.

\section{Variation in body mass and crop size of chicks in captivity}

For the eight chicks captured with turgid crops we estimated the mass of the food received by each chick as the differences in body mass between the first and last recording for that individual. The val- ues of food mass were square root-transformed to normalize them. A mixed linear model (Pinheiro

\& Bates 2000) was used to test the effect of crop size on food mass. Chick identity was fitted as a random factor in this model.

We also used mixed effects models to assess the effects of tarsus length, final body mass of chicks, food mass and the interactions of these variables with time from capture on variation in crop size; chick identity was fitted as a random factor. Ordi- nal multinomial regression was used to analyse variation in crop size categories (McCullagh 1980, Agresti 1996, Vermunt \& Hagenaars 2004). Unlike conventional logistic models in which the dependent variable is a dichotomy, ordinal models are applied to $\mathrm{J}$ responses measured on an ordinal scale, and these models make use of cumulative logits. The model produces $\mathrm{J}-1$ probability func- tions with different independent terms and a com- mon slope. To determine the factors related to variation in crop size, we started with a model that included all explanatory variables and succes- sively eliminated those that were not significant, starting with the interaction terms. We present only the results of the significant effects. To con- duct the ordinal multinomial logistic models we

used GLIMMIX in SAS 9.1.3 (SAS Institute Inc. 2006).

Spearman's rank correlation coefficient was used to assess associations among variables. We tested for significant differences between the times elapsed from capture to estimation of both body mass and crop size stabilization, using Wilcoxon matchedpairs signed-rank test. Since the sample size was small $(n=8)$, exact probabilities were utilized in both tests (StatXact, Cytel Inc. 2005).

\section{Annual variation in body mass and crop size}

Annual variation in crop size categories recorded from 1998 to 2009 was analysed using the likelihood ratio test. Mean annual body condition of chicks ringed in 1998-2009 ( $\mathrm{n}=7581)$ was estimated from the residuals of a regression model of body mass on tarsus length. First, using a secondorder polynomial regression we assessed whether the relationship between body mass of chicks and tarsus length was non-linear. The quadratic term was not significant when applied on the whole dataset $\left(\mathrm{t}_{1}=0.79, \mathrm{P}=0.428\right)$. When the data for each year were analysed separately, the quadratic term was significant in only 4 of the 10 years. Therefore, we used a linear model to control for the effect of chick size on body mass. We also used an analysis of covariance to assess the effect of crop size on the body mass of chicks (García-Berthou 2001), in which we included tarsus length as a covariate. Previously, we assessed whether the interaction tarsus length - crop size was significant, which would indicate that for the same crop profile category the mass of the food would vary with chick size. Once the significant effects in the model were determined, we calculated the residuals of body mass for every individual after controlling for the effects of tarsus length and crop size. Using Student's paired t-test we compared the residuals of a model that included only tarsus length with those of another model that included tarsus length and crop size. The relationship between the annual percentages of crop size categories and mean annual values of body condition indexes (mass residuals) after controlling for crop size was estimated using Pearson correlations, weighting each observation by sample size (Neter et al. 1996), with the aim of avoiding the problem that the calculation of the coefficients could be affected by data precision. 
To assess daily variation in the frequencies of crop categories within a season, we used the likelihood ratio test $\left(\mathrm{G}^{2}\right)$. For this, in 2003 we recorded in the early morning the crop profiles of individually marked chicks during a period of five consecutive days (from 3 to 7 August 2003). We chose this period to avoid repeated sampling of chicks fed by the same adult, as individual adults visit the breeding site every 6 days on average to feed their chicks (see Discussion). Unless otherwise stated, means are given \pm 1 sd.

\section{RESULTS}

\section{Inter-observer agreement for crop} scores

Results show that unweighted test values for different colonies suggest moderate agreement when assessing crop size among different observers: Odiel Salt Pans: $40 \%$ of exact agreement between cases, $\mathbf{j}=0.558$ (CI $95 \%=0.416-0.648)$; Marismas del Guadalquivir: $\quad 30 \%, \quad \mathbf{j}=0.487 \quad$ (0.355-0.603); Fuente de Piedra Lake: $30 \%, \mathbf{j}=0.516 \quad$ (0.3710.632). However, when the size of the disagreement was taken into account, the weighted Kappa values suggest that agreement among different observers was higher: Odiel Salt Pans: $\mathbf{j w}=0.815$ (CI 95\% = 0.706-0.882); Marismas del Guadalquivir: $\mathbf{j w}=0.838$ (0.777-0.879); Fuente de Piedra Lake: $\mathbf{j w}=0.865 \quad(0.760-0.908)$. This improvement in the inter-observer agreement when we use $\mathbf{j} \mathbf{w}$ was because the inter-observer scores never varied by more than one category.

\section{Variation in mass and crop size in captive chicks}

The mean value of the absolute body mass loss of chicks during the fasting period (i.e. the mass of the food) was $393 \pm 90 \mathrm{~g}$ (range 250-550 g; Table 1), representing $18 \pm 6 \%$ (range 15-29\%) of the final body mass of chicks. Absolute and relative individual variation in the mass of individual feeds was not related to tarsus length (Spearman's correlations: $\left.\mathrm{n}=8 ; \mathrm{r}_{\mathrm{s}}=\right)$ )0.15, $\mathrm{P}=0.724 ; \mathrm{r}_{\mathrm{s}}=$ ) 0.33, $\mathrm{P}=0.419$, respectively) or to the final body mass of chicks $\left.\left(n=8 ; r_{s}=\right) 0.20, P=0.610 ; r_{s}=\right) 0.69$, $\mathrm{P}=0.067$, respectively).

The mean time elapsed from the first recording until constant body mass (final body mass) was not different from the time elapsed until the crop was 
Table 1. Body measurements of Greater Flamingo chicks captured with their crops full and maintained in captivity. The following values are shown: tarsus length, body mass at both capture $\left(\mathrm{M}_{\mathrm{i}}\right)$ and release times $\left(\mathrm{M}_{\mathrm{f}}\right)$, absolute and proportional values of body mass loss during the experiment relative to the final body mass (DM), and time elapsed from capture to both body mass stabilization (no differences between two consecutive recordings) $\left(\mathrm{TM}_{0}\right)$ and when the crops were empty $\left(\mathrm{TC}_{0}\right)$.

\begin{tabular}{|c|c|c|c|c|c|c|}
\hline Individual & $\begin{array}{c}\text { Tarsus } \\
(\mathrm{cm})\end{array}$ & $\begin{array}{l}M_{i} \\
(g)\end{array}$ & $\begin{array}{l}M_{f} \\
(g)\end{array}$ & $\begin{array}{c}\text { DM } \\
\text { (g) (\%) }\end{array}$ & $\begin{array}{l}\mathrm{TM}_{\mathrm{O}} \\
\text { (h) }\end{array}$ & $\begin{array}{l}\mathrm{TC}_{0} \\
\text { (h) }\end{array}$ \\
\hline 이JFB & 18.9 & 2200 & 1900 & $300(16)$ & 17 & 11 \\
\hline 이NPL & 21.0 & 2800 & 2400 & 400 (17) & 16 & 16 \\
\hline O|NSA & 21.6 & 2250 & 1850 & $400(22)$ & 20 & 17 \\
\hline 이PCD & 25.8 & 3000 & 2750 & $250(9)$ & 11 & 11 \\
\hline 이PCF & 21.0 & 3000 & 2600 & 400 (15) & 7 & 11 \\
\hline 이PZN & 20.5 & 2450 & 1900 & 550 (29) & 14 & 14 \\
\hline 이RCP & 25.0 & 3150 & 2700 & 450 (17) & 16 & 20 \\
\hline 이RIL & 22.7 & 2850 & 2450 & 400 (16) & 19 & 22 \\
\hline Mean & 22.0 & 2656 & 2300 & 393 (18) & 15 & 15 \\
\hline sd & 2.0 & 341 & 379 & 90 & 4 & 4 \\
\hline
\end{tabular}

Table 2. Ordinal logistic mixed model estimates, standard error (se) and significance for the variation of crop sizes in Greater Flamingo chicks captured with their crops full as a function of time. Chick identity was included as a random factor.

\begin{tabular}{lrrrr}
\hline Factor & Coefficients & se & $\mathrm{t}$ & $\mathrm{P}$ \\
\hline Constant 0 & ) 11.02 & 2.33 & ) 4.73 & 0.002 \\
Constant 1 & ) 7.17 & 1.79 & ) 4.02 & 0.005 \\
Constant 2 & ) 4.31 & 1.46 & ) 2.96 & 0.021 \\
Time & 0.77 & 0.15 & 5.15 & $<0.001$ \\
\hline
\end{tabular}

empty $(15 \pm 4 \mathrm{~h}$; Wilcoxon matched pair test: $\mathrm{P}=0.813$; Table 2 and Fig. 2). Feed mass varied with crop profile category $\left(r^{2}=0.78, \quad F_{3,36.1}=\right.$ 37.2, $\mathrm{P}<0.001$ ). The mean mass (least square means) of food stored for each crop profile category was $2.4 \mathrm{~g}(95 \% \mathrm{CI}=2.1-20.7)$ for crop profile 0 , $34.0 \mathrm{~g}(10.2-71.5)$ for crop profile $1,99.8 \mathrm{~g}$ (48.9-168.7) for crop profile 2 and $292.9 \mathrm{~g}$ (221.7-378.0) for crop profile 3.

The temporal variation in crop size depended on the time elapsed since the chicks were captured but did not depend on tarsus length, final body mass of chicks, feed mass or the interactions of these variables with time (Table 2). An ordinal logistic model of crop profile categories as a function of time indicates that for individuals captured with turgid crops, the allocation of crop to profile category 3 is more likely during the first $6 \mathrm{~h}$, to profile category 2 between 6 and 9 h, to profile category 1 between 13 and $14 \mathrm{~h}$ and to profile category 0 from 13 to
$14 \mathrm{~h}$ after the capture (Fig. 3). Thus, it took 13$14 \mathrm{~h}$ for chicks to empty their crops.

\section{Inter-annual variation in crop size}

During 1998-2009, on average $33.7 \pm 6.2 \%$ (range 23.8-41.5\%) of chicks had empty crops, $34.7 \pm 4.9 \%(31.0-42.5 \%)$ had crops allocated to profile category 1, $18.2 \pm 3.3 \%(15.5-25.4 \%)$ had crops assigned to profile category 2 and $13.4 \pm 4.3 \%$ (8.3-21.8\%) had crops allocated to profile category 3 (Fig. 4). There was significant inter-annual variation in crop profile categories $\left(G_{27}^{2} 1 / 4267: 6, P<0.001\right)$. However, there was no significant variation in crop profile categories during five consecutive days in a single season $\left(G_{12}^{2} 1 / 48: 68, \quad P=0.730 ; \quad\right.$ Fig. 5). Thus, although provisioning rates differed among years, there were no significant daily differences within a season.

\section{Effect of crop profile on body condition}

A linear regression including tarsus length as independent variable explained $52 \%$ of the variance in body mass (slope body mass-tarsus length: $15.35 \pm 0.17$ se, $\left.F_{1,7640}=8202.7, P<0.001\right)$. The interaction tarsus length - crop size was not significant $\left(F_{3,7572}=1.1, P=0.338\right)$. When tarsus length and crop profile category were included in the linear model, the effect of both variables was significant and explained $56 \%$ of the variance in body mass (slope body mass-tarsus length: $15.10 \pm 0.16$ se, $F_{1,7585}=8647.6, P<0.001$; crop size: $\left.F_{3,7585}=262.1, P<0.001\right)$.

There was inter-annual variation in the effect of the quantity of food delivery on the index of body condition when the average yearly residuals of body mass on tarsus length were compared, depending on whether the effect of crop profile was included in the models (Fig. 5). Thus when body mass was not corrected for crop profile, body condition was overestimated in 1999 and 2000, and underestimated in 2003, 2004 and 2006. These annual differences between both indexes of body condition were related to the proportion of chicks with large crop sizes (mean annual difference vs. the annual percentage of chicks with crop profiles 3 and $2+3: \mathrm{n}=10 ; \mathrm{r}_{\mathrm{s}}=0.89, \mathrm{P}<0.001$ and $r_{s}=0.93, P<0.001$, respectively). In spite of the significant inter-annual variation in the average residuals of body mass depending on whether the effect of crop profile was included in the model, 

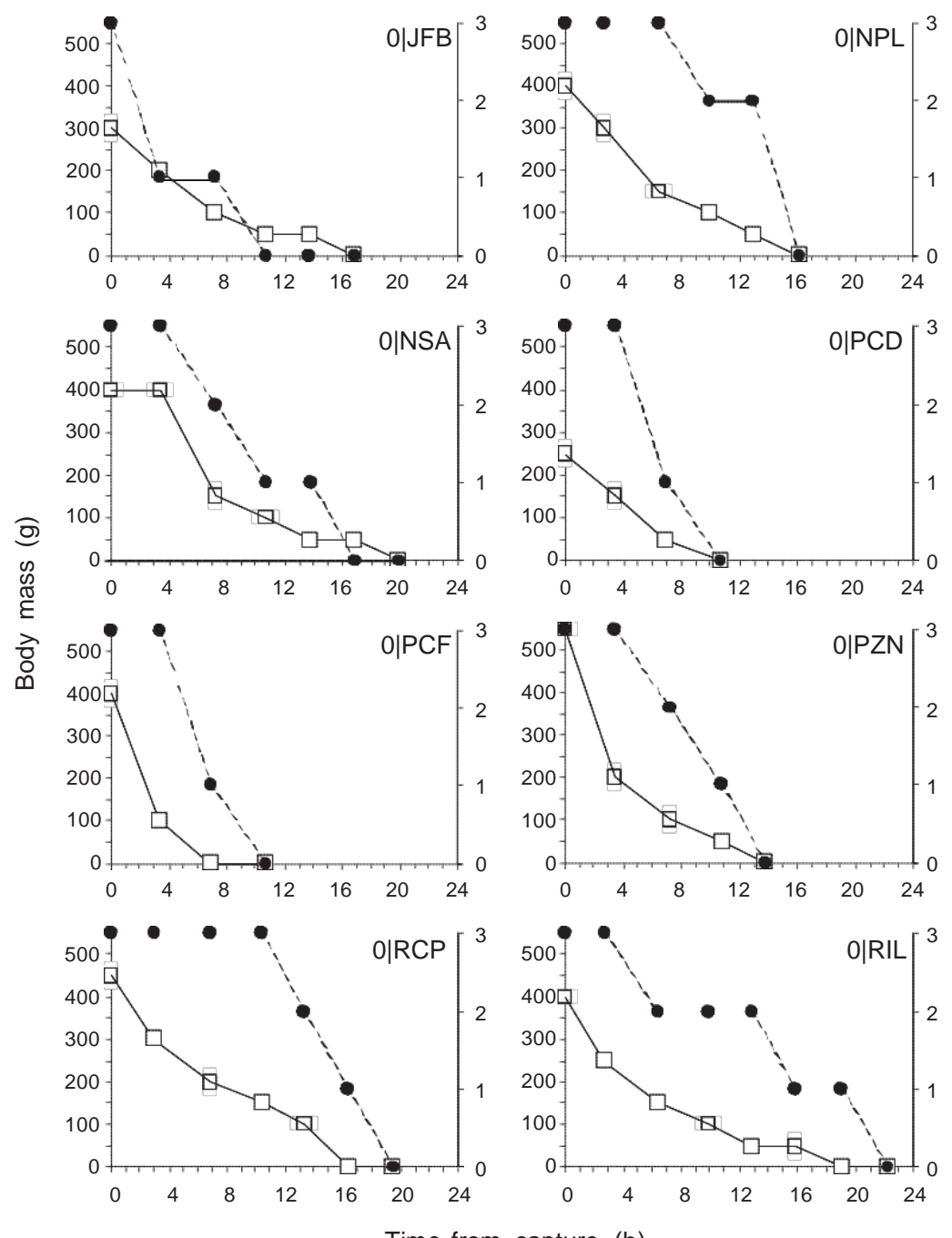

Time from capture $(\mathrm{h})$

Figure 2. Temporal variation in both body mass relative to the asymptotic final body mass (h) and the crop size (d) in eight Flamingo chicks captured with their crops full. Ring codes for each individual are shown.

there were no differences in the relative position of such values because of large annual differences in body condition.

\section{Frequencies of crop profile-body condition relationship}

There were no significant relationships between the mean annual body condition indexes, corrected for crop size, and the annual proportion of chicks with crop profile 0 (weighted Pearson correlation: $\mathrm{n}=10, \quad \mathrm{r}=0.13, \mathrm{P}=0.711)$, profile $2(r=0.35$, $P=0.329)$ and profile $3(r=0.46, P=0.183)$, or with the proportion of chicks fed during the night (crop profile categories $2+3 ; r=0.54, P=0.109$ ).
However, mean annual body condition was negatively correlated with the percentage of chicks with crop profile $1(r=) 0.79, \mathrm{P}=0.007)$.

\section{DISCUSSION}

Changes in body masses of Greater Flamingo chicks were related to changes in the categories of crop profiles. Thus, these categories of relative crop size may be used as reliable indicators of the amount of food in a chick's crop. The mass of feeds was independent of chick size. Cézilly et al. (1994) found that the time that adults took to provision their chicks, and hence perhaps the food mass, was related to chick age. The lack of such 


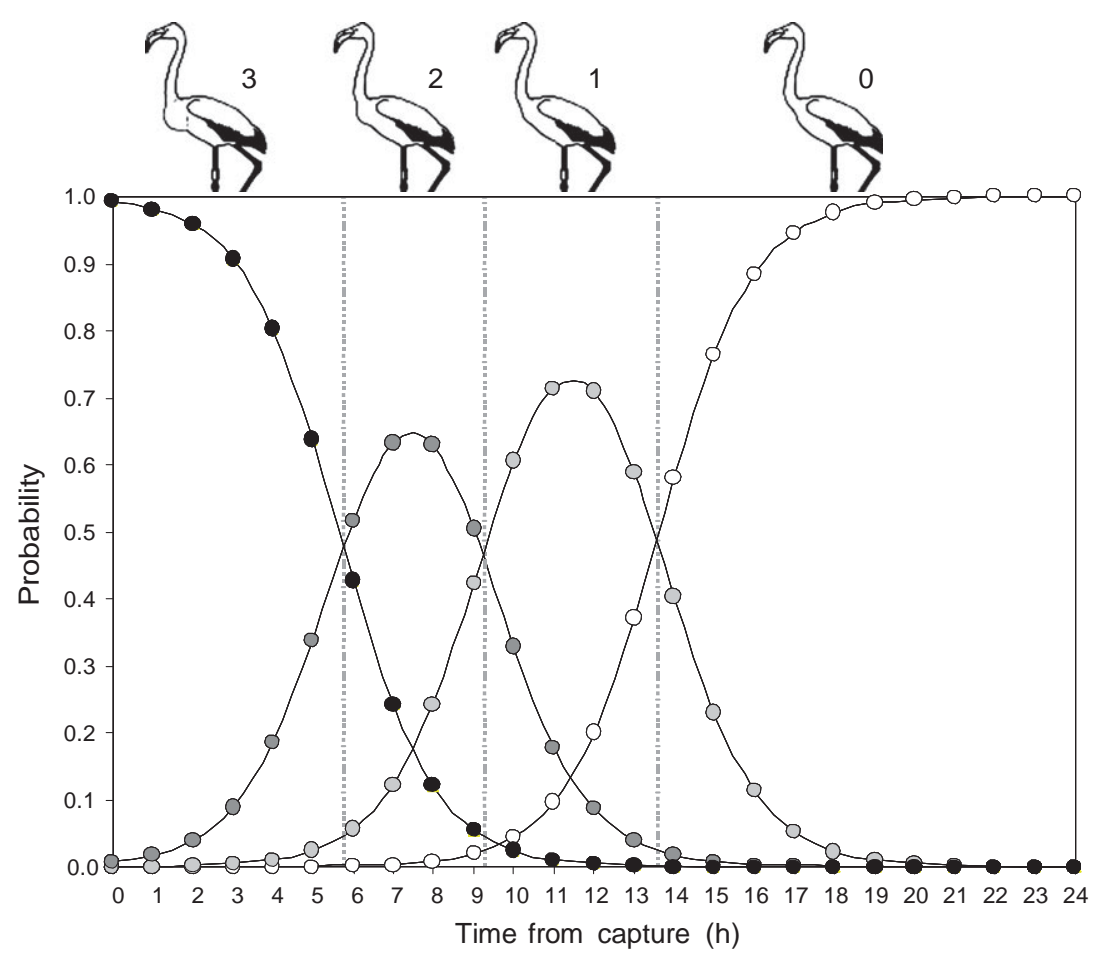

Figure 3. Graph of the ordinal logistic model for the crop size variation in Greater Flamingo chicks captured with their crops full, as a function of time of fasting.

a relationship in our study may be due to the fact that we studied only large chicks ( $>7$ weeks old), which had completed about two-thirds of their development. In captive American Flamingos Phoenicopterus ruber the mass of food received by chicks increases linearly with age until the chicks are 5 weeks old, and thereafter stabilizes (Burch \& Gailband 2000). During the last phase of a chick's development, the capacity of adults to produce the feeding secretions may limit the quantity of food with which they are able to provision their chicks.

\section{Effects of crop content on body condition estimations}

Despite the low precision of our body mass measurements $( \pm 50 \mathrm{~g}$, which represents $2.3 \%$ of average chick body mass), the inclusion of individuals with crop profiles allocated to categories 2 and 3 would overestimate the net body masses in onethird of chicks, probably because the mass of feeds was on average $18 \%$ of the body mass of chicks. Nevertheless, such overestimation due to the crop content depended on inter-annual variation in the proportion of crop size categories. When mass-tarsus residuals are used as a body condition index, the effect of crop size on body mass would not have affected inter-annual differences in body condition estimation if the proportions of fed chicks were constant among years. Thus, in years in which there was a greater proportion of chicks with larger crop sizes than the mean for the whole study period, body condition was overestimated. In contrast, in years when there was a greater proportion of empty crops than the mean for the study period, body condition was lower than that estimated after controlling for crop size.

The effect of crop size on the estimation of body condition of Flamingo chicks has been accounted for in one study (Amat et al. 2007) but not in others (Barbraud et al. 2003, Béchet \& Johnson 2008). Our results show that in spite of significant interannual variation in the indexes of body condition after controlling for crop size, the relative position of the body condition estimators did not depend on whether crop size was controlled for. This may be because the inter-annual variation in the body condition of chicks as a consequence of the amount of food in their crops represented only $4 \%$ of the average annual variation in the body mass of chicks. 

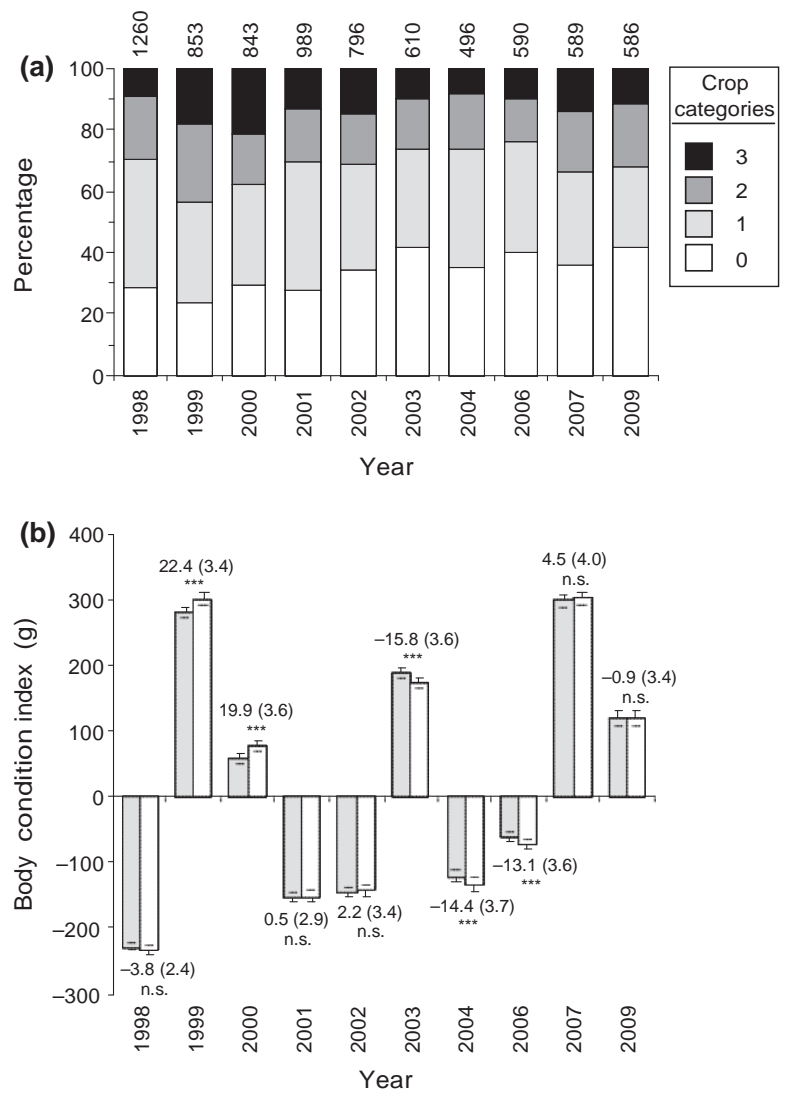

Figure 4. (a) Percentages of crop size categories to which Greater Flamingo chicks marked at Laguna de Fuente de Piedra colony from 1998 to $2009(n=7586)$ were allocated. Sample sizes are shown for each year. (b) Mean annual ( \pm se) body condition values (residuals from the linear models tarsus length-body mass (white bars) and tarsus length + crop size category-body mass (grey bars)). Numbers on bars indicate mean annual differences (standard error) between both indices. Significant annual differences are shown (n.s.: $\mathrm{P}>0.05$; $\star \star \star P<0.001)$.

\section{Crop size as a provisioning index}

From absorption times of crop content it was possible to infer the time at which the chicks were fed. Obviously, this estimation is only valid if, after being fed, the crop of a chick is completely full. This assumption is plausible, as most chicks (7080\%) had turgid crops after being fed (M.A. Rendón, A. Garrido, J.A. Amat, M. Rendón-Martos \& J.M. Ramírez, unpubl. data).

The time of day at which the chicks are fed provides information on provisioning patterns. A part of the feed takes place at dusk, just before the adults depart from the breeding site to foraging areas, whereas other chicks are fed during the night,

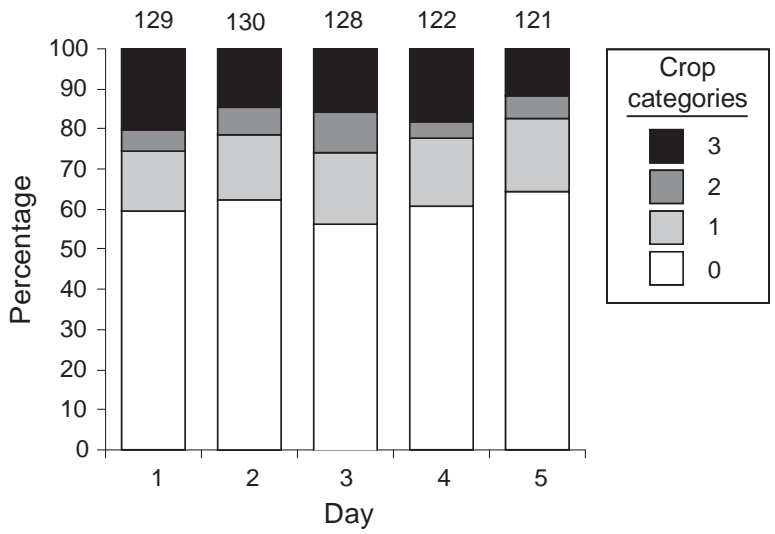

Figure 5. Percentages of crop size categories to which Greater Flamingo chicks were allocated during five consecutive days in 2003 (day 1: August 3). Sample sizes are shown above the bars.

when the adults that spent several days in foraging areas return to the breeding site (Rendón-Martos et al. 2000, Amat et al. 2005). As chicks are as a rule captured at dawn, it is likely that chicks with crops allocated to profiles 2 and 3 had been fed during the night, whereas chicks with crops assigned to category 1 had been fed late the previous afternoon. Therefore, about one-third of chicks were fed at dusk and another third during the night. These proportions are consistent with the commuting patterns of adults during the chick-provisioning period. After feeding the chicks, the adults move back to foraging areas, where they remain on average for 6 days (Amat et al. 2005). Because both sexes provision their chick, and assuming that there are not sexual differences in commuting patterns, a parent is expected to arrive at the colony one night in three. Moreover, the number of adults that remain during the day at the breeding site is onethird of the number of chicks (Rendón-Martos et al. 2000) and they are likely to provision their chicks just before returning to the adult foraging areas.

The inter-annual variation in the proportions of crop categories may be used to assess the effects of environmental variation and social factors on provisioning patterns, even if the data are obtained during a single day every year. Although in some cases for birds inhabiting highly variable environments it may not be possible to establish provisioning patterns from short-duration observation periods (Weimerskirch et al. 2001), in other cases it has been shown that provisioning patterns may 
be accurately determined when the sampling is conducted over very short time periods (Benson et al. 2003). In the case of the Greater Flamingo we have shown that provisioning patterns, as determined by crop profile categories, were consistent among days during the last third of the provisioning period. Furthermore, Amat et al. (2007) have shown that there is a negative relationship between average annual crop profiles and plasma cholesterol in Greater Flamingo chicks, indicative of longer fasting periods.

\section{Body condition and provisioning patterns}

Our results show that the average annual condition of chicks was not related to the percentage of chicks that were fed the night prior to their capture (i.e. those with crop profile categories 2 and 3 ), but to the percentage of chicks that were fed at dusk the day before their capture (i.e. those with crop profile category 1 ). When the number of days that adults remain in foraging areas increases, the time that they remain in the breeding site before commuting increases (data from four satellitetracked adults, Spearman rank correlation coefficient: $r_{\mathrm{s}}=0.88, \quad \mathrm{n}=11$ commuting sessions, $P<0.001$; J.A. Amat, M.A. Rendón, M. RendónMartos, A. Garrido \& J.M. Ramírez, unpubl. data). Usually, those adults that remain in the foraging areas for 4-6 days return to foraging areas after chick provisioning either during the same night as they commuted, or the following day after commuting, whereas the adults that spent eight or more days in foraging areas usually remain for 2 days at the breeding site before commuting again (Amat et al. 2005). When adults remain for more than 1 day in the colony they may feed their chick during the daytime in order to increase the probability of detecting potential predators (Beauchamp \& McNeil 2003). Therefore, the relationship between body condition and the proportion of chicks with crop profile category 1 would indicate that the chicks fed during diurnal hours are in part an indicator of the time that adults spent both at the breeding site and in foraging areas, which is inversely related to provisioning frequencies and may not be compensating for the mass of the feeds, as has been found in other species that forage great distances from a centrally placed breeding site (Weimerskirch et al. 1997, Granadeiro et al. 1998, Gray \& Hamer 2001).
Our results suggest that a crop profile index can be a useful measure of the amount of food stored by the chicks, thus enabling both estimation of more accurate body condition metrics and providing a means with which to infer chick provisioning patterns. In this study, we have only analysed crop size scores obtained from chicks captured during the ringing process. However, because the variation in crop size is perceptible from a distance, it is also possible to collect a larger number of samples using telescopes. This information, combined with the individual identification of banded chicks, makes it possible to study seasonal and interannual provisioning strategies and their relationship with both demographic and environmental factors applying longitudinal approaches, using markresighting modelling procedures.

We express our appreciation to the many volunteers who over the years helped with the captures and banding operations of Flamingo chicks. During this long-term study we received financial support through agreements between the Consejería de Medio Ambiente and both the University of Málaga and Consejo Superior de Investigaciones Científicas, as well as from research projects BOS2002-04695 and CGL2005-01136/BOS of Dirección General de Investigación with EU-ERDF support, and RNM361 of Junta de Andalucía. M.A.R. was supported by an introductory research grant from the University of Málaga during the first few years of the study.

\section{REFERENCES}

Agresti, A. 1996 An Introduction to Categorical Data Analysis. New York: John Wiley \& Sons.

Amat, J.A., Rendón, M.A., Rendón-Martos, M., Garrido, A. \& Ramírez, J.M. 2005. Ranging behaviour of Greater Flamingos during the breeding and post-breeding periods: linking connectivity to biological processes. Biol. Conserv. 125: 183-192.

Amat, J.A., Hortas, F., Arroyo, G.M., Rendó n, M.A., Ramírez, J.M., Rendó n-Martos, M., Pérez-Hurtado, A. \& Garrido, A. 2007. Interannual variations in feeding frequencies and food quality of Greater Flamingo chicks (Phoenicopterus roseus): evidence from plasma chemistry and effects on body condition. Comp. Biochem. Physiol. 147A: 569-576.

Barbraud, C., Johnson, A.R. \& Bertault, G. 2003. Phenotypic correlates of post-fledging dispersal in a population of greater flamingos: the importance of body condition. J. Anim. Ecol. 72: 246-257.

Barlow, K.E. \& Croxall, J.P. 2002. Provisioning behaviour of Macaroni Penguins Eudyptes chrysolophus. Ibis 144: 248258.

Batty, M., Jarrett, N.S., Forbes, N., Brown, M.J., Standley, S., Richardson, T., Oliver, S., Ireland, B., Chalmers, K.P. \& Fraser, I. 2006. Hand-rearing Greater Flamingos Phoenicopterus ruber roseus for translocation from WWT Slimbridge to Auckland Zoo. Int. Zoo Yearbook 40: 261270. 
Beauchamp, G. \& McNeil, R. 2003. Vigilance in Greater Flamingos foraging at night. Ethology 109: 511-520.

Béchet, A. \& Johnson, A.R. 2008. Anthropogenic and environmental determinants of Greater Flamingo Phoenicopterus roseus breeding numbers and productivity in the Camargue (Rhone delta, southern France). Ibis 150: 69-79.

Benson, J., Suryan, R.M. \& Piatt, F.J. 2003. Assessing chick growth from a single visit to a seabird colony. Mar. Ornithol. 31: 181-184.

Blockstein, D.E. 1989. Crop milk and clutch size in Mourning Doves. Wilson Bull. 101: 11-25.

Bolton, M. 1995. Food delivery to nestling Storm Petrels: limitation or regulation? Funct. Ecol. 9: 161-170.

Burch, L. \& Gailband, C. 2000. Comparison of hand-reared Caribbean Flamingos and Lesser Flamingos at Seaworld California. Waterbirds 23: 193-197.

Cézilly, F., Tourenq, C. \& Johnson, A. 1994. Variation in parental care with offspring age in the Greater Flamingo. Condor 96: 809-812.

Collopy, M.W. 1986. Food consumption and growth energetics of nestling Golden Eagles. Wilson Bull. 98: 445-458.

Comeau, R.M. \& Keppie, D.M. 1988. Crop weights used to adjust body weights of live Spruce Grouse. J. Wildl. Manage. 53: 818-819.

Conger, A.J. 1980. Integration and generalisation of Kappas for multiple raters. Psychol. Bull. 88: 322-328.

Cytel Inc. 2005. StatXact. 7 PROCs. Statistical Software for Exact Nonparametric Inference, User Manual, 7th edn. Cambridge, MA: Cytel Software Corporation.

Dawson, R.D. \& Bortolotti, G.R. 2002. Experimental evidence for food limitation and sex-specific strategies of American Kestrels (Falco sparverius) provisioning offspring. Behav. Ecol. Sociobiol. 52: 43-52.

Drent, R.H. \& Daan, S. 1980. The prudent parent: energetic adjustment in avian breeding. Ardea 68: 225-252.

Falissard, B. 2009. psy: Various procedures used in psychometry. R package version 1.0. http://cran-project.org/web/ packages/psyl.

García-Berthou, E. 2001. On the misuse of residuals in ecology: testing regression residuals vs. the analysis of covariance. J. Anim. Ecol. 70: 708-711.

Granadeiro, J.P., Nunes, M., Silva, M.C. \& Furness, R.W. 1998. Flexible foraging strategy of Cory's Shearwater, Calonectris diomedea, during the chick-rearing period. Anim. Behav. 56: 1169-1176.

Granadeiro, J.P., Burns, M.D. \& Furness, R.W. 1999. Food provisioning to nestling shearwaters: why parental behaviour should be monitored? Anim. Behav. 57: 663-671.

Gray, C.M. \& Hamer, K.C. 2001. Food-provisioning behaviour of male and female Manx Shearwaters, Puffinus puffinus. Anim. Behav. 62: 117-121.

Hamer, K.C., Lynnes, A.S. \& Hill, J.K. 1998. Regulation of chick provisioning rate in Manx Shearwaters: experimental evidence and implications for nestling obesity. Funct. Ecol. 12: 625-630.

Houston, D.C. \& Houston, D.C. 1976. Breeding of the Whitebacked and Rüppell's Griffon Vultures (Gyps africanus and G. rueppellii). Ibis 118: 14-40.

Johnson, A.R. \& Cézilly, F. 2007. The Greater Flamingo. London: T \& AD Poyser.
Landis, J.R. \& Koch, G.G. 1977. The measurement of observer agreement for categorical data. Biometrics 33: 159-174.

Lang, E.M. 1963. Flamingoes raise their young on a liquid containing blood. Experientia 19: 532-533.

Lecomte, N., Kuntz, G., Lambert, N., Gendner, J.-P., Handrich, Y., Le Maho, Y. \& Bost, C.-A. 2006. Alloparental feeding in the King Penguin. Anim. Behav. 71: 457-462.

McCullagh, P. 1980. Regression models for ordinal data. J. R. Stat. Soc. B 42: 109-142.

Neter, J., Kutner, M.H., Nachtsheim, C.J. \& Wasserman, W. 1996. Applied Linear Statistical Models. Chicago: Irwin.

Ojowski, U., Eidmann, C., Furness, R.W. \& Garthe, S. 2001. Diet and nest attendance of incubating and chick-rearing Northern Fulmars (Fulamarus glaciaris) in Shetland. Marine Biol. 139: 1193-1200.

Phillips, R.A. \& Hamer, K.C. 2000. Periodic weighing and the assessment of meal mass and feeding frequency in seabirds. J. Avian Biol. 31: 75-80.

Pinheiro, J.C. \& Bates, D.M. 2000. Mixed-Effects Models in S and S-Plus. New York: Springer.

Rendón, M.A., Garrido, A., Amat, J.A. \& Rendón-Martos, M. 2009. Monitoring of Greater Flamingo colonies: some proposals for measuring and interpreting results. Flamingo Spec. Publ. 1: 62-75.

Rendón-Martos, M., Vargas, J.M., Rendón, M.A., Garrido, A. \& Ramírez, J.M. 2000. Nocturnal movements of breeding Greater Flamingos in southern Spain. Waterbirds 23: 9-19.

Ricklefs, R.E., Day, C., Huntington, C. \& Williams, J. 1985. Variability in feeding rate and meal size of Leach's stormpetrel at Kent Island, New Brunswick. J. Anim. Ecol. 54: 883-898.

SAS Institute Inc. 2006. Base SAS 9.1.3 Procedures Guide, 2nd edn. Cary, NC: SAS Institute Inc.

Smith, T.B. 1990. Resource use by bill morphs of an African finch: evidence for intraspecific competition. Ecology 71: 1246-1257.

Smith, T.B. 1991. Inter- and intraspecific diet overlap during learn times between Quelea erythrops and bill morphs of Pyrenestes ostrinus. Oikos 60: 76-82.

Vermunt, J.K. \& Hagenaars, J.A. 2004. Ordinal longitudinal data analysis. In Hauspie, R.C., Cameron, N. \& Molinari, L. (eds) Methods in Human Growth Research: vol. 15: 374393. Cambridge: Cambridge University Press.

Weimerskirch, H., Cherel, Y., Cuenot-Chaillet, F. \& Ridoux, V. 1997. Alternative foraging strategies and resource allocation by male and female Wandering Albatrosses. Ecology 78: 2051-2063.

Weimerskirch, H., Zimmermann, L. \& Prince, P.A. 2001. Influence of environmental variability on breeding effort in a long-lived seabird, the Yellow-nosed Albatross. Behav. Ecol. 12: 22-30.

Westmoreland, D. \& Best, L.B. 1987. What limits Mourning Doves clutch of two eggs? Condor 89: 486-493.

Ziswiler, V. \& Farner, D.S. 1972. Digestion and the digestive system. In Farner, D.S. \& King, J.R. (eds) Avian Biology, Vol. II: 403-430. New York: Academic Press. 